\title{
A GUERRA LONGE DO FRONT: OS DESDOBRAMENTOS DA I GUERRA MUNDIAL NA AMÉRICA LATINA
}

DOI: http://dx.doi.org/10.15448/2178-3748.2015.1.19168

\author{
Heitor de Andrade Carvalho Loureiro \\ Doutorando - UNESP/Franca \\ E-mail: heitorloureiro@gmail.com
}

COMPAGNON, Olivier. O Adeus à Europa: a América Latina e a Grande Guerra. Tradução de Carlos Nougué. Rio de Janeiro: Rocco, 2014, 399 p.

Efemérides sempre acarretam uma série de eventos acadêmicos e lançamentos editoriais, que se aproveitam das datas para preencher as agendas e abastecer as estantes com títulos relacionados a um determinado evento tido como relevante. O ano de 2014 foi particularmente profícuo nesse sentido; no contexto nacional, os cinquenta anos do Golpe de 1964 foram relembrados por eventos de todos os tipos; no plano internacional, o acontecimento mais significativo foi, sem dúvida, o centésimo aniversário do início da Grande Guerra.As maiores livrarias do país ficaram abarrotadas de inúmeros títulos recémlançados sobre a Grande Guerra. Dentre eles, chama a atenção O Adeus à Europa do historiador francês Olivier Compagnon, professor de história contemporânea da Université Sorbonne Nouvelle - Paris 3.

É pertinente começar esta resenha pelo título escolhido: O Adeus à Europa: A América Latina e a Grande Guerra. Há que se destacar que o título original em francês foi traduzido ipsis litteris para o português, com a exceção de um segundo subtítulo no qual se lê “Argentine et Brésil, 1914-1939”. A omissão na edição brasileira prejudica, de certa maneira, a coerência do título com relação ao conteúdo, na medida em que, além de fornecer o recorte temporal adotado pelo autor, a segunda sentença mitigaria a generalização feita no primeiro subtítulo. O livro de Compagnon não trata da importância da Grande Guerra em toda a América Latina, mas se concentra numa abordagem de história comparada sobre os impactos da Guerra na Argentina e no Brasil. É certo que a escolha dos casos de análise é bem justificada: são dois países expressivos no subcontinente, que ocupavam lugares semelhantes no sistema internacional pré-1914, além de vivenciarem nas primeiras quatro décadas do século XX questionamentos semelhantes no que tange à identidade nacional. Ademais, as relações bilaterais entre Argentina e Brasil sofriam interferência da forma com que cada país se relacionava com os EUA, a Europa e, após 1914, com a Guerra. Dessa forma, uma análise 
das consequências da Grande Guerra nos dois países ajuda também a compreender, para além dos impactos da Guerra propriamente ditos, como Buenos Aires e Rio de Janeiro construíram sua política externa vis-à-vis a ameaça do outro.

A pesquisa de Compagnon é movida pela necessidade de contestar interpretações de que a América Latina não haveria experimentado os efeitos da Grande Guerra a partir de 1914 e tampouco teria se mobilizado de forma relevante para o conflito e, por isso, se justificaria o silêncio que há na historiografia sobre as consequências do conflito na porção meridional do Atlântico. O historiador francês afirma que esse silêncio não é compatível com a vasta documentação disponível sobre o período da Guerra e da Liga das Nações, o que indica que o conflito mundial foi um ponto de inflexão na história de Argentina e Brasil cujas consequências seriam sentidas até 1939. Para o autor, a lacuna historiográfica pode ser creditada a uma abordagem excessivamente militar do conflito que destaca os aspectos do front de batalha em detrimento do que acontecia longe das trincheiras, além de uma tendência da historiografia latino-americana de realizar análises nacionais pouco propensas à história comparada ou global.

O cerne da tese do autor é o entendimento de que a Grande Guerra - tida como o "suicídio da Europa" - causou uma crise de identidade na América Latina que tinha no Velho Continente um modelo, produzindo, por conseguinte, o distanciamento de Buenos Aires e Rio de Janeiro das capitais europeias. Para Compagnon, a reação das elites latino-americanas ao suicídio europeu seria o nacionalismo, sobretudo na esfera da cultura, com a valorização do passado colonial, dos povos nativos e da trajetória rumo ao Estado-nação, cujo ápice pode ser identificado, no caso brasileiro, na Semana de Arte Moderna de 1922.

O principal corpus documental analisado pelo autor é formado por periódicos de ampla circulação em Buenos Aires e Rio de Janeiro, além de documentação diplomática oriunda de arquivos europeus e americanos. Dos periódicos, são explorados tanto os artigos e editoriais, quanto o material iconográfico que traduz em imagens as impressões dos principais órgãos de imprensa de Argentina e Brasil acerca da Guerra. Entretanto, não fica claro quais foram os arquivos consultados por Compagnon para ter acesso aos periódicos trabalhados, nem sequer se são oriundos de pesquisa física ou a partir de plataformas como a Hemeroteca Digital Brasileira da Biblioteca Nacional. Essa informação seria útil para os que desejem explorar alguma temática pouco abordada pelo autor. As demais fontes utilizadas nessa pesquisa estão devidamente referenciadas, embora o sistema de notas no final do livro tenha excluído a listagem das referências bibliográficas, o que também beneficiaria o leitor que desejasse consultar rapidamente as obras usadas pelo historiador francês, ao invés de ter que

Oficina do Historiador, Porto Alegre, EDIPUCRS, v. 8, n. 1, jan./jun. 2015, p. 90-98. 
achá-las em meio às notas, não obstante a existência de um índice onomástico que facilita a localização dos principais personagens do período.

O livro contém sete capítulos divididos em três partes. Na primeira parte, intitulada $D a$ guerra europeia à guerra americana, Compagnon mostra como o aparente desinteresse do continente americano pelo conflito mundial nos seus primeiros meses foi substituído aos poucos por disputas pelo engajamento ou neutralidade das nações americanas na Grande Guerra, a medida que o conflito dava sinais de que duraria mais do que apenas alguns meses, conforme era esperado inicialmente.

O capítulo 1 - a neutralidade dos Estados - mostra como a opinião pública latinoamericana, muito voltada para os EUA quando se tratava de política externa, pouco repercutiu o assassinato do arquiduque austríaco em Sarajevo e deu apenas um espaço secundário nas páginas dos jornais para os artigos distribuídos pelas agências Reuters e Havas, que cobriam os primeiros confrontos da guerra. Segundo o autor, as elites latino-americanas encaravam a Guerra como um "conflito europeu", cujo desenrolar interessava menos do que os problemas regionais que ameaçariam o status quo do lado de cá do Atlântico, como a Revolução Mexicana, no caso do mais setentrional dos países da América Latina, e da integração de índios, negros e outras minorias no Brasil, onde o medo da secessão sempre pairava no ar.

Entretanto, a intensificação das batalhas na Europa e a saída de cena de líderes sulamericanos que advogavam neutralidade ante ao conflito - como Roque Saeñz Peña na Argentina e Hermes da Fonseca no Brasil - alteraram substancialmente a percepção da Guerra no Rio de Janeiro e em Buenos Aires. Ainda que a neutralidade de ambos os países tenha sido mantida e reafirmada, começaram a surgir nas páginas dos jornais debates entre germanóflios, anglófilos/francófonos e neutralistas pela postura que os governos deveriam tomar no desenrolar do conflito. Aquelas vozes que defendiam o engajamento na Guerra foram rapidamente tomadas como irresponsáveis pelas classes políticas argentinas e brasileiras, amedrontadas diante da possibilidade de que a participação no conflito prejudicasse o modelo agroexportador que dependia do maior número de mercados possíveis, além do receio de que a tomada de posição pudesse iniciar um processo desagregador catalisado pelas comunidades imigrantes que habitavam Brasil e Argentina. De acordo com Compagnon, o perigo estrangeiro gerou na Argentina uma tentativa de valorização da cultura local como forma de criar uma identidade regional que mitigasse o background europeu da população - cerca de metade dos 11 milhões de imigrantes europeus que aportaram na América Latina entre 18241924 se dirigiram para aquele país. No Brasil, o medo residia numa comunidade não muito numerosa - cerca de 400 mil - mas bastante coesa: os alemães no Sul do país, cuja

Oficina do Historiador, Porto Alegre, EDIPUCRS, v. 8, n. 1, jan./jun. 2015, p. 90-98. 
possibilidade de secessão tirava o sono de intelectuais como Sílvio Romero. Assim, a neutralidade era desejada e vista como necessária, desde que fosse uma "neutralidade ativa", cujo mote era tirar vantagem sem tomar partido, aproximando ambos os países da política externa norte-americana, nação essa que o governo brasileiro acreditava tera missão de conduzir a paz na Europa ao final da Guerra.

No capítulo 2 - a mobilização das opiniões - Olivier Compagnon disserta sobre o começo do abandono da política neutralista para a adoção da defesa do engajamento em um dos lados da Guerra. O autor destaca como a imprensa gradualmente adotou o discurso aliadófilo em detrimento dos argumentos neutralistas e germanófilos. Destaca-se o pertencimento dos donos dos órgãos aos setores das elites tradicionalmente aliados da GrãBretanha e que tentavam defender os interesses britânicos. Essa tomada de posição nas páginas dos jornais foi acompanhada por um discurso de imputação de culpa aos Impérios Centrais e, sobretudo, à Alemanha, pela eclosão do conflito e por suas consequências devastadoras. O sentimento antigermânico foi consolidado em grupos de interesses como a Liga Brasileira pelos Aliados, fundada em março de 1915, contando com Graça Aranha como mandatário e Rui Barbosa como presidente de honra. Contudo, não é prudente, conforme o autor indica, inferir que o sentimento aliadófilo estava presente em toda a sociedade brasileira, uma vez que era fortemente reproduzido nos círculos intelectuais e da elite, que colocavam a questão nos termos de uma guerra da "civilização contra a barbárie". Em nome desta “civilização", entre 1.200 e 1.800 latino-americanos se alistaram como voluntário nas forças francesas, além dos inúmeros atos em apoio à França, "mãe" das artes e de todas as liberdades, cuja principal cidade era também a "capital do mundo".

Porém, as vozes dissonantes eram expressivas o suficiente para serem escutadas. Entre os neutralistas, havia desde socialistas que encaravam o conflito como uma guerra capitalista, até intelectuais como Oliveira Lima cuja análise sóbria do conflito refutava qualquer tentativa de analisar a Grande Guerra por meio da chave de leitura que contrapunha civilização e barbárie. Os germanófilos encontravam apoio, principalmente, nas fileiras das Forças Armadas, sobretudo no grupo conhecido como "Jovens Turcos", cuja proximidade com o modo prussiano de fazer a guerra foi lapidada a partir de visitas às casernas alemãs. Nesse ponto, caberia uma análise mais detalhada sobre a trajetória dos Jovens Turcos por parte do autor, que se furta de fazê-la, alegando que faltam pesquisas a esse respeito, ainda que José Murilo de Carvalho, João Quartim de Moraes e teses de doutorado mais recentes tenham abordado o assunto em maior ou menor grau. $\mathrm{O}$ apoio à Alemanha era especialmente vigiado e temido quando emanava do Sul do Brasil, onde a questão do duplo pertencimento dos teuto- 
brasileiros preocupava as autoridades. Os cerca de vinte jornais em língua alemã que circulavam no país no início da Guerra exacerbavam o sentimento de que, em caso de uma mobilização lançada por parte do Kaiser, as colônias do Sul poderiam se levantar contra o Rio de Janeiro.

No início do terceiro capítulo, intitulado As Américas em Guerra, o autor elabora análises sobre questões econômicas que rondavam o conflito e influenciavam no tamanho do envolvimento de Brasil e Argentina na Guerra. Segundo o historiador, a partir de 1915 os impactos econômicos do conflito foram sentidos de forma mais intensa na América Latina, o que foi acompanhado de um crescente interesse da imprensa e das elites para o que acontecia na Europa. Compagnon destaca como a tendência inflacionária, a instabilidade monetária, a redução dos investimentos em infraestrutura e a execução das dívidas contraídas pelos bancos europeus em empréstimos contraídos pelos latino-americanos foram fatores desestabilizastes para as economias ao Sul do Atlântico. A economia argentina conseguia manter certo dinamismo graças às exportações de carne e trigo para a Europa, mas a pouco diversificada economia brasileira, dependente do café na razão de $2 / 3$ das exportações, levou o país a se questionar se a neutralidade no conflito seria, de fato, a melhor estratégia. A carestia aumentou a agitação social nas principais cidades do país, o que provocou uma greve geral em 1917 que ajudou a desestabilizar o governo.

O conturbado contexto socioeconômico aliado à guerra submarina alemã, que causava danos ao comércio exterior e à navegação de pessoas no Atlântico, fez com que a neutralidade não mais fosse considerada vantajosa pelos tomadores de decisão no Brasil. Ademais, a iminente entrada dos EUA no conflito ao lado dos Aliados pressionava os países latinoamericanos a tomar o mesmo partido, alegando "solidariedade continental". De abril a outubro de 1917, o sistemático torpedeamento de navios mercantis brasileiros fez com que o Congresso brasileiro aprovasse o "estado de guerra" contra o Império Alemão, já visando figurar, na opinião do autor, no rol das nações vencedoras em caso de derrota alemã. Em Buenos Aires, por outro lado, a situação se desenrolou de maneira diferente, ainda que o cenário fosse semelhante ao brasileiro. Apesar do rompimento de relações de Uruguai, Bolívia e Equador com a Alemanha, além da declaração de guerra do Brasil, o mandatário argentino Hipólito Yrigoyen manteve o que foi chamado de "neutralidade benevolente" ao aceitar as desculpas alemãs por ter afundado embarcações argentinas, mas não tomar nenhuma atitude mais enérgica contra Berlim, apesar das manifestações de solidariedade feitas aos países aliados. Uma das razões apontadas por Compagnon para essa postura é o sentimento anglofóbico presente nas elites argentinas, aliadas ao nacionalismo exacerbado 
que fora fomentado por Buenos Aires a fim de diminuir o risco de regionalismos e estrangeirismos no país. Ainda segundo o autor, a própria Grã-Bretanha teria preferido que a Argentina não se envolvesse na Guerra tal como fez o Brasil, para evitar que Washington aumentasse a sua influência sobre Buenos Aires no desenrolar do conflito. Seja qual tenha sido a posição adotada, ambos os países respiraram aliviados quando os tiros cessaram na Europa. Para além das questões econômicas e diplomáticas, "a guerra ofereceu oportunidade", nas palavras do autor, "para uma ampla reflexão sobre a natureza das relações estabelecidas com a Europa desde o início do século XIX e sobre a validade de um modelo de civilização que se mostrou capaz de sacrificar 10 milhões de seus filhos na lama das trincheiras" (COMPAGNON, 2014, p.158).

É justamente a reflexão sobre o conflito europeu o tema da segunda parte da obra de Olivier Compagnon - A Europa bárbara - na qual o autor mostra como a "modernidade importada" da Europa para a América Latina marcou o continente desde a independência até a belle époque, marco civilizatório que sofreu sérias rachaduras com a Grande Guerra a ponto de permitir que experiências alternativas de modernidade brotassem por entre as frestas do modelo europeu. Em Os horrores da Guerra, quarto capítulo do livro, o historiador defende que o front de batalha não era a única forma de vivenciar o conflito, pois mesmo à distância a perplexidade pelo que ocorria na Europa tomava as mentes daqueles que se dedicavam a acompanhar o que foi chamado de conflagração, deflagração, catástrofe, grande tragédia, grande cruzada, a maior guerra dos séculos, colossal conflito belicoso, cataclismo universal, dentre outras alcunhas.

No capítulo 5 - Noturno europeu - elabora-se a visão que permeava alguns intelectuais latino-americanos de que a Europa estava em seu crepúsculo, enquanto a América se preparava para ser o lócus da civilização no pós-Guerra. A preocupação de jornalistas como Júlio de Mesquita e João do Rio com o final da Guerra e o despertar de uma nova era refletia, assim, as questões que deveriam pautar a inserção do Brasil na nova ordem mundial que se desenhava, na qual os EUA desempenhavam um papel protagonista e novas experiências organizacionais surgiam, como a Liga das Nações. Durante as comemorações pelo centenário das independências de Argentina (1916) e Brasil (1922) falava-se que havia chegado a hora de uma "segunda independência" latino-americana, quando a "emancipação intelectual" era desejável e inevitável. Essa emancipação epistêmica deveria ser seguida por uma política externa incisiva que buscasse ocupar os espaços decisórios do sistema internacional, não obstante o alinhamento com os EUA. Nesse sentido, a participação do país na Conferência de Paz de Paris em 1919, sentado ao lado das nações vencedoras do conflito, 
foi encarada pela imprensa como uma vitória diplomática brasileira, principalmente quando comparada à postura argentina de se manter neutra na Guerra e como observadora, tanto em Paris quanto na Liga das Nações. Essa diferença de atitude elevava o moral do país na disputa particular com o seu maior vizinho. Apesar de Olivier Compagnon afirmar, ainda na introdução, que Argentina e Brasil tiveram comportamentos distintos durante a Guerra, mas vivenciaram "uma experiência absolutamente idêntica perante a Liga das Nações" (COMPAGNON, 2014, p.25), a análise das trajetórias de ambos os países no organismo de Genebra mostra que a segunda parte da afirmação do historiador francês não se sustenta. De fato, Buenos Aires deixou de ter interesse pelas discussões da Liga a partir de 1920, quando suas propostas de emendas ao Pacto da entidade foram derrotadas, mas nunca se desligou formalmente da entidade, mantendo uma postura discreta. Por outro lado, a atuação do Brasil na Liga das Nações foi marcada pela proatividade - e até mesmo certa agressividade sobretudo na busca de um assento permanente no Conselho da entidade, instância na qual ocupou uma vaga rotativa durante praticamente todo o período em que permaneceu em Genebra até o desligamento em 1926, após vetar a entrada da Alemanha na entidade e falhar na consecução do posto pretendido, cinco anos e meio após a Argentina ter deixado de frequentar as assembleias.

A terceira parte do livro contém o cerne do argumento do autor. Em Grande Guerra, a nação, a identidade, Compagnon argumenta que o conflito não foi crucial para as ressignificações identitárias apenas na Europa, mas também na América Latina, em um movimento de ruptura causado pela Guerra que provocou uma "renovação nacionalista" tanto na política quanto no campo da cultura. No sexto capítulo - A cristalização política da nação - o historiador francês afirma que os nacionalismos de Argentina e Brasil gestados no pósguerra foram decisivos para os regimes autoritários que subiriam ao poder em ambos os países nos anos 1930. Questões como o problema racial e da miscigenação estiveram na ordem do dia de intelectuais e teóricos dos dois lados da fronteira naquele momento, bem como o papel da religião cristã e católica para o cidadão e a sociedade - em contrapartida ao protestantismo alemão no Brasil e o judaísmo na Argentina, ambos representantes de forças tidas como desagregadoras nessas sociedades - além de acalorados debates sobre os rumos das economias nacionais e o grau de envolvimento com o capital estrangeiro.

Uma cultura da guerra, sétimo e derradeiro capítulo do livro, versa sobre a "virada cultural" que a América Latina experimentou, na qual "o papel da Grande Guerra merece ser seriamente avaliado" (COMPAGNON, 2014, p.284). Para o autor, a Guerra ajudou a criar uma autonomia intelectual à América Latina em relação à Europa, sobretudo no Brasil, onde a 
Semana de Arte Moderna abalou as fundações do entendimento do que seria a "cultura nacional". Todavia, Compagnon ressalta, pertinentemente, que a Guerra não rompeu totalmente com os padrões europeus, mas provocou uma reconfiguração dessa relação, colocando-a em termos mais críticos e menos espelhados. O autor cita como exemplo dessa ruptura parcial as missões francesas que ajudaram a constituir a Universidade de São Paulo, principalmente os cursos de Ciências Humanas. A valorização do patrimônio histórico e arquitetônico brasileiro bem como do passado colonial e da cultura popular demonstra que pessoas como Mário de Andrade pensavam na importância de se definir que havia cultura e história também do lado de cá do Atlântico, não obstante a insistência das elites em buscarem referências culturais emanadas de Paris.

$\mathrm{Na}$ conclusão, Compagnon reafirma sua tentativa de mostrar uma lacuna historiográfica, no que tange às análises sobre os impactos da Grande Guerra na América Latina, que não se justifica quando se explora os arquivos. Para ele, ao invés de enxergar o período entre 1889-1929 como um período contínuo, é necessário perceber o ponto de inflexão causado pela Guerra em 1914. Usando as palavras do próprio autor para sintetizar seu argumento: "Sem dúvida possível, a Grande Guerra foi um momento-chave no longo decurso do século XX na Argentina e no Brasil. [...] A América Latina que o mundo consome diariamente neste início do século XXI construiu sua alteridade no rasto da Grande Guerra" (COMPAGNON, 2014, p.323; 331).

De fato, o mérito de Compagnon está em deter-se no desenrolar de um grande acontecimento que, quando não é excluído das análises, é mencionado apenas en passant em manuais da política externa brasileira ou como pano de fundo em análises da política interna. Sua análise comparativa entre Brasil e Argentina mostra-se válida apontando, principalmente, as semelhanças de trajetórias entre as duas nações na primeira metade do século $\mathrm{XX}$. A estratégia utilizada pelo autor em não separar a obra por países, mas por temas, dentro dos quais ele analisa simultaneamente ambos os casos nacionais, demonstrou-se acertada, tornando a leitura mais agradável, ainda que em determinados momentos aconteça uma sobreexploração de um país em detrimento do outro. Há que se verificar as consequências da Guerra em outros países da América Latina, sobretudo no México, para saber se algumas das generalizações feitas por Compagnon realmente se sustentam quando observada uma amostragem maior de nações americanas. Por ora, resta o reconhecimento de que o autor avançou no entendimento dos impactos socioculturais da Guerra, notadamente no Brasil, campo esse que outras análises não apreenderam, muito por conta de serem trabalhos de 
história diplomática baseados em documentos de arquivos como os do Ministério de Relações Exteriores.

RESENHA ENVIADA EM: 28/10/2014 ACEITA PARA PUBLICAÇÃO EM: 08/04/2015 